\title{
Promoting Tobacco Cessation and Smoke-Free Workplaces Through Community Outreach Partnerships in Puerto Rico
}

\author{
Elba C. Díaz-Toro, DMD, MSD, $\mathrm{MPH}^{1}$, Maria E. Fernández, $\mathrm{PhD}^{2}$, Virmarie Correa-Fernández, $\mathrm{PhD}^{3}$, William A. Calo, JD, $\mathrm{MPH}^{4}$, \\ Ana Patricia Ortiz, MPH, PhD ${ }^{5}$, Luz M. Mejía, MA ${ }^{3}$, Carlos A. Mazas, PhD³ , María del Carmen Santos-Ortiz, MA, MPHE, CHES, PhD \\ David W. Wetter, $\mathrm{PhD}^{3}$
}

(1) School of Dental Medicine and Puerto Rico Comprehensive Cancer Center, University of Puerto Rico, Medical Sciences Campus; (2) Health Promotion and Behavioral Sciences, University of Texas Health Science Center at Houston, School of Public Health; (3) Department of Health Disparities Research, University of Texas MD Anderson Cancer Center; (4) Institute for Health Policy, University of Texas Health Science Center at Houston, School of Public Health; (5) Graduate School of Public Health, University of Puerto Rico, Medical Sciences Campus

Submitted 17 September 2012, revised 20 February 2013, accepted 12 April 2013.

\section{Abstract}

Background: Puerto Rico (PR) has a lower smoking prevalence than the United States $(14.8 \%$ vs. $21.2 \%$, respectively); nevertheless, the five leading causes of death are associated with smoking. There is a need to implement evidence-based tobacco control strategies in PR.

Objectives: The Outreach Pilot Program (OPP) was designed to engage communities, health professionals, and researchers in a network to advance health promotion activities and research to increase the use of the PR Quitline (PRQ) among smokers and promoting policies in support of smoke-free workplaces.

Methods: Using community-based participatory research (CBPR) methods, the OPP mobilized a network of community and academic partners to implement smoking cessation activities including referrals to the PRQ, adoption of evidence-based smoking cessation programs, and promotion of smoke-free legislation.

Results: Eighty organizations participated in the OPP. Collaborators implemented activities that supported the promotion of the PRQ and smoke-free workplaces policy and sponsored yearly trainings, including tobacco control conferences. From 2005 to 2008, physician referrals to the PRQ increased from $2.6 \%$ to $7.2 \%$. The number of annual smokers receiving cessation services through the PRQ also increased from 703 to 1,086 . The OPP shepherded a rigorous smoke-free law through participation in the development, promotion, and implementation of the smoke-free workplaces legislation as well as the creation of the PR Tobacco Control Strategic Plan, launched in 2006.

Conclusions: This project demonstrates the feasibility of developing a successful and sustainable community-based outreach program model that enlists the participation of academic researchers, community organizations, and health care providers as partners to promote tobacco control.

\section{Keywords}

Smoking cessation, quitlines, community outreach, community-based participatory research, health disparities
A lthough the prevalence of smoking in Puerto Rico is lower than in the United States (14.8\% vs. $21.2 \%),{ }^{1}$ the public health burden of smoking in PR is substantial. Recent data show that three of the five leading causes of death in PR are associated with smoking. ${ }^{2}$ Relative to the United States, several unique smoking- related health disparities exist. ${ }^{3}$ For example, the incidence of tobacco-related oral and pharyngeal cancers among men in PR is higher than among Hispanic, non-Hispanic Black, and non-Hispanic White men in the United States. ${ }^{4}$ In fact, oral cancer incidence among men in PR is the highest in the Western hemisphere $\left(10.6\right.$ per 100,000.0). ${ }^{5}$ Despite the clear 
need for evidence-based tobacco control interventions, access to smoking cessation treatment and promotion of smoke-free environments in PR was limited. According to the Puerto Rico Substance Abuse Treatment Needs Assessment Study, 98.2\% of the women and $82.3 \%$ of the men in need of substance abuse treatment, including tobacco cessation, receive no services for their substance use. ${ }^{6}$ Additionally, legislation did not cover all workplaces, such as casinos and some restaurant areas. Thus, a more comprehensive policy was needed to protect both employees and nonsmokers from the negative consequences of second-hand smoke.

In response to the need for greater access to and availability of tobacco control interventions, the PR OPP was developed. Strategies to address the gap in tobacco control included establishing a collaborative network among diverse organizations in PR to advocate for tobacco control initiatives, increase use of the $\mathrm{PRQ}$, and promote a comprehensive workplace smoke-free policy.

\section{SMOKING CESSATION QUITLINES}

Smoking cessation significantly reduces the risk of suffering from smoking-related illness and death. ${ }^{7-9}$ Both the U.S. Centers for Disease Control and Prevention and the Treating Tobacco Use and Dependence Clinical Practice Guideline have identified smoking cessation quitlines as efficacious, cost effective, and successful at increasing the reach of cessation treatments. ${ }^{7} 10-13$ The telephone counseling provided by quitlines can overcome many of the barriers to obtaining adequate health care often faced by smokers. ${ }^{14}$ Telephone counseling is convenient for delivering person-to-person behavior change interventions and has the potential to reach a large number of smokers. Telephone counseling is also cost effective and inexpensive relative to in-person interventions. It often is free for the patients (as in PR); requires less time commitment than other approaches; overcomes geographic isolation; requires no travel, childcare, or parking; and is offered in Spanish. The standard quitline telephone counseling has some distinguishing features including proactive counseling, a structured counseling protocol, and relapse-sensitive scheduling. ${ }^{15,16}$ The content of the counseling addresses both behavioral and cognitive issues the individual smoker faces in an attempt to quit. With the help of U.S. Centers for Disease Control and Prevention funding, the PR Department of
Health established the PRQ, which began operations in late December 2004. The PRQ is a member of the North American Quitlines Consortium and provides free, proactive telephone counseling to all PR smokers interested in quitting. ${ }^{17}$

Unfortunately, quitlines are often grossly underutilized, in part owing to a lack of health care and community awareness of the PRQ phone number and the kind and quality of services available through them, especially in the absence of expensive advertising campaigns. ${ }^{18-21}$ Other barriers to quitline use include the need of multiple sessions of telephone counseling, which in turn requires regular and private access to a telephone, as well as other resources that are not available to all smokers. ${ }^{22}$ Addressing this lack of knowledge and credibility could significantly boost the proportion of smokers who are able to successfully quit when regularly referred by the health care community. One way to increase the reach of these services is to harness the health care system to identify and refer smokers to quitlines proactively. ${ }^{12,23}$ Recognizing the potential of quitlines for improving smoking cessation in PR, the OPP sought to enhance awareness and use of the PRQ among smokers and increase referral to quitlines among health care professionals.

Although media campaigns are an effective strategy for generating calls to quitlines, ${ }^{24-28}$ they are often costly and produce temporary rather than sustained increases in calls..$^{24,29-33}$ Thus, alternative strategies for increasing awareness and use of the PRQ were necessary. The development of community and health care partnerships can facilitate the dissemination of evidence-based health promotion interventions including tobacco quitlines. ${ }^{34-42}$ Organizations that include tobacco cessation and control in their own strategic plans and goals and who have direct and frequent contact with the community are ideally suited to participate in such efforts.

\section{WORKPLACE SMOKE-FREE POLICY}

Previous studies have demonstrated that workplace smoking bans decrease smoking prevalence and intensity, and increase cessation. A meta-analysis of 26 studies revealed that smoking prevalence decreased by $3.8 \%$, and cigarette consumption by 3.1 cigarettes per day after implementation of bans. ${ }^{29-33}$ Moreover, Healthy People 2010 included a goal to increase smoking bans to cover $100 \%$ of all workplaces. ${ }^{34}$ Thus, another goal of the OPP was to advocate for policies to ban 
smoking in all workplaces in PR. Our approach was consistent with those recommended by the literature. Evidence suggested that the likelihood of local policy adoption of smoking-related laws is higher when the local health community promotes the efforts. ${ }^{43}$ We used the evidence-based recommended approaches described to promote smoke-free workplace policies. ${ }^{44,45}$ OPP staff and network members helped author the actual legislation; we participated in public hearings in both chambers and also developed and distributed educational materials to increase awareness in the community about the importance and public health impact of smoke-free workplace legislation. The OPP also worked with policymakers and advocacy community members to recruit more volunteers to promote the smoke-free workplace legislation.

\section{METHODS}

\section{OPP Overview}

CBPR and capacity-building models guided the development of the network and the implementation of OPP activities $^{34-42}$ (Table 1). The OPP sought to work within the existing community, health care, and government organization infrastructures to increase the sustainability of outreach efforts. The CBPR approach helped to ensure that the needs, interests, and values of the community were reflected, that programs were adapted and delivered in a culturally competent manner improving the likelihood of dissemination and sustainability.$^{35-40,43-45}$ An OPP guiding principle was that activities reflect evidence-based approaches shown to affect behavior change. Smoke-free public policies and quitlines have demonstrated efficacy for increasing smoking cessation and secondhand smoke exposure ${ }^{12,29,43-45}$; and increasing awareness, promotional campaigns, and partnering with health care providers increase quitline calls. . $^{2-28,35,46-48}$

The OPP carried out the following types of activities: 1) Network development, 2) research, 3) training and education, and 4) community awareness. Following the CBPR model, community organizations played an active role in defining the problem, choosing intervention approaches, determining program activities, collecting data, and evaluating and disseminating findings. OPP partners shared objectives, plans, and reported activities with the PR Department of Health Tobacco Control officials, the PRQ administrators, and the community during national and local conferences and local community based organization meetings. Additionally, we used existing dissemination infrastructures, such as network organizations web pages, to disseminate the PRQ information. Data produced through OPP efforts provided needs assessment information necessary to identify priority populations in PR and continue developing efforts to promote the PRQ services.

Network Development. With funding from the National Cancer Institute, the OPP began in 2005 as a partnership between the University of Puerto Rico-Medical Sciences Campus, the University of Texas M. D. Anderson Cancer Center, and the Puerto Rico Department of Health. The OPP recruited a broad array of partner organizations that serve diverse populations in PR, and that would, in turn, identify additional partners and engage in cancer and tobacco control outreach activities, training/education opportunities, and public education programs implemented by the OPP.

Key leaders from identified organizations were invited to an initial network meeting as part of the 2005 Tobacco Control Summit (Cumbre de Tabaquismo 2005; CT05). This summit, organized by the Tobacco Control Office of the PR Department of Health since 2002, aims to educate and increase awareness of the tobacco use burden in PR and promote the dissemination of tobacco control evidence-based programs and policies in PR. The OPP has become an active supporter of this annual summit and has contributed to making it an opportunity for increased collaboration, education, training, and the development of new OPP activities around tobacco control. For example, during CT05 action groups were formed and were responsible for creating their own plans to promote and increase the use of the PRQ and to support smoke-free policy changes. These action groups also participated in the development of the overall strategic plan for future OPP activities. A steering committee (SC) was created to guide and advise OPP activities including the identification of "champions" to support promotion of the PRQ and smoke-free workplaces legislation.

SC members were selected based on: 1) membership in a community-based or provider organization, 2) interest in becoming a member of the SC, and 3) network members' acceptance and approval. The SC drafted the strategic plan for the OPP, oversaw action group activities, served as the organizing committee for network activities, and served as the liaison between the OPP staff and the community-based 
Table 1. Project Phases and Timeline (September 2005 to August 2008)

Phases

Activities

Phase 1: Pre-Project

October 2004-

January 2005

September 2005

( defining the problem, choosing intervention approaches, determining project activities. Proposal design, proposal writing and submission. Develop evaluation instruments and logic model.

Pilot OPP granted: Receiving funding. Refine study and procedures based consultant recommendations and findings, IRB approval for special activities, Design material for trainings and promotion activities. PRQ Counselors training.

Phase 2: 0-3 Months

November 2005-

December 2005

Summit 2005: Key leaders from identified organizations were invited to an initial network development activities in how to promote the PRQ and the smoke-free policy efforts.

First official OPP Network meeting: Steering committee and action group were developing. Training in collecting the data and evaluating findings and disseminating results and smoke-free policy promotion. Writing of the PR smoke-free workplaces legislation project.

PSA media tour promoting the PRQ and smoke-free legislation.

Phase 3: 4-25 Months

January 2006

February 2006

Participation in the smoke-free workplaces legislation public hearings and promotion activities and media tour.

Summit 2006: Research activities evaluation of secondary data analysis from the BRFSS and PRQ to drive the PRQ promotion efforts, training and education activities for network members and health professionals in how to promote and refer smokers to the PRQ.

March 2006 Approval and PR governor sing of the smoke-free workplaces legislation in PR.

April 2006

PRQ counselors MI trainings.

May 2006

Development and submission of new alcohol and tobacco control pilot trial with the PRQ grant proposal.

June-February 2007 Evidence-based practices for tobacco control trainings for the network.

Implementation activities for promoting the smoke-free law with youth and the PRQ to health professionals. Implementation of new alcohol and tobacco control pilot trial with the PRQ grant proposal.

March 2007 Collecting the data of pre-legislation implementation findings in restaurants and casinos.

April 2007 Implementation of the smoke-free workplaces law in PR.

December 2007

Collecting the quantitative data about evidence-based practice implementation by the network, collecting qualitative data among the SC members to evaluate the OPP project development processes and evaluating pre and post legislation findings in restaurants and casinos.

Summits 2007: Ask, advice, connect training for health professionals and network members. Disseminating results of some network members' dissemination activities in posters presentations.

Writing of the Smoking Cessation Coverage by all Health Insurance legislation project.

Phase 4: 26-36 Months

January 2008

Participation in the Smoking Cessation Coverage by all Health Insurance legislation public hearings and promotion activities.

February 2008 Approval and PR governor signing of the Smoking Cessation Coverage by all Health Insurance legislation.

March $2008 \quad$ First anniversary of the PR Smoke-free law promotion activities and media tour.

PRQ counselors MI buster training.

April-July 2008 Development of PSA short film and radio PRQ announcement.

Dissemination of preliminary results of OPP project and the tobacco and Alcohol treatment pilot trial.

August 2008

Brief intervention for smoking cessation in 2008 Summit: International Tobacco Control PR Summit to disseminate the PR experience implementing the Smoke-free workplaces law and the OPP activities with other Hispanic countries.

Complete final evaluation, data analysis, and national dissemination of results.

BRFSS, Behavior Risk Factor Surveillance Survey; CBPR, community-based participatory research; IRB, institutional review board; MI, motivational interviewing; OPP, Outreach Pilot Program; PRQ, PR Quitline; PSA, public service announcement. 
network partners. OPP staff facilitated network functioning by coordinating communication among network members and the SC, assessing network training needs, and developing and planning trainings for network members. OPP staff, together with network members, also created educational and promotional materials for the PRQ and helped to plan and organize the tobacco summits.

Research Activities. The OPP sought to build research partnerships, capacity, and conduct pilot studies that would lead to community-based participatory research in cancer control in PR. A major objective of the OPP was the creation of infrastructure for future research, including academiccommunity partnerships. It was important to have the PRQ personnel and partners including the PR Department of Health, the American Cancer Society, the UPR Tobacco Control Center, and PR Lung Association and other stake holders interested in policy research engaged as part of the OPP network and the planning stage period. For example, PRQ counselors, administrators, and data management staff received training to adapt the existing PRQ infrastructure for future research projects. The network policy working group received training in policy research, including process, impact, and outcome evaluations of smoke-free policies. The OPP also collaborated with community partners on the submission of research proposals. We conducted a pilot study to determine the feasibility of conducting an intervention trial for smoking cessation and alcohol use with the tobacco quitline. This provided data that supported a recently completed National Institutes of Health-funded research study. ${ }^{49}$ Building on the infrastructure developed during the pilot, we have conducted a number of other research studies with OPP partners. For example, we examined the demographic and smoking-related characteristics of the individuals served by the PRQ to better identify subgroups of smokers who may be underserved by this smoking cessation service. ${ }^{17} \mathrm{We}$ also assessed the effect of the smoke-free workplace policy on the exposition to secondhand smoke in restaurants, pubs, and casinos in PR. ${ }^{50,51}$

Training and Educational Interventions. The purpose of the OPP training and education activities were to build competencies in tobacco control for network members; develop training programs for health-care professionals particularly on system changes for tobacco cessation, and to develop and offer specialized training for the PRQ counselors. The OPP trained community leaders and stakeholders to increase the knowledge and skills needed to take action and to sustain tobacco control approaches over time. Trainings for health care providers focused on systems changes included a tobacco cessation tool kit designed to help physicians and other health professionals incorporate tobacco cessation strategies and system changes into their clinical practices.

The OPP also conducted workshops for network members on methods of promoting and implementing evidence-based practices for tobacco control and effective strategies to promote smoke free workplaces policies such as: the support of key decision makers, emulation of comparable jurisdictions, ${ }^{52}$ alignment of the policy with the local political climate, ${ }^{53}$ the presence of "political entrepreneurs" and strong advocacy organizations. ${ }^{54,55}$ Other approaches highlighted by a recent study ${ }^{56}$ were also used: 1) Having a "champion" who helped to carry an objective forward, 2) tapping into a pool of potential volunteers, 3) collecting and using local data as a persuasive tool, 4) educating the community in smoke-free policy efforts, 5) working strategically in the local political climate, and 6) framing the policy appropriately.

Community Awareness. Community awareness activities included development of promotion and communication products, public education activities promoting the PRQ use for the general public and health professionals, and tobacco control and smoke-free workplace policy promotional activities. The OPP developed PRQ educational materials, referral materials, a health professional PRQ referral starting kit, newsletters, and web pages. The network worked extensively on the development of public service announcements and educational materials with the PRQ logo. These products also included messages in support of smoke-free workplace policy changes. OPP staff and network members helped to author the smoke-free workplace policy legislation, participated in public hearings, and developed and distributed educational materials to increase awareness in the community about the importance and public health impact of smoke-free workplace legislation. The OPP also worked with policymakers and advocacy community members to recruit more volunteers to promote the smoke-free workplace legislation. 


\section{Network Development and Evaluation}

Forty-five representatives from 32 organizations participated in CT05 and chose to join the OPP network. Over the next 2 years, other partners joined to reach a membership of 80 unique organizations. The SC included 12 members who met quarterly. The SC created the mission statement, bylaws, and media press coverage plan. The SC also coordinated meetings, worked with budget allocations for network activities, and reacted to critical events during the smoke-free law approval process. The SC participated in the development of the PR Tobacco Control Strategic Action Plan. The SC held quarterly meetings; the network met twice a year. The network sustained momentum by regular communication and meetings with members, continued recruitment, and orientation of new members and new collaborations. For example, Telemedik, the company that administers the PRQ services through a contract from the PR Department of Health, established a close collaboration with the OPP. OPP staff provided Telemedik with training for PRQ counselors and consulting support for data management. Network members also promoted OPP goals and activities at their professional events, and provided input for program initiatives. The OPP conducted and evaluation of network functioning which included brief surveys ${ }^{57}$ and indepth interviews with the $\mathrm{SC}$ members at the end of the project.

The OPP developed a logic model that provided a frame- work for evaluation considering inputs, activities, and outcomes. Inputs are the resources used to accomplish the goals of the OPP and include OPP researchers, community and other partners, the SC, students and community volunteers, and other community partners. The activities (network development, research, training, and education) targeted health care organizations and providers and community organizations. The "Output" section of the logic model includes the immediate products, capacity, programs, and new resources produced by OPP activities. The network development activities were designed to produce a cooperative partnership with a common mission-to reduce tobacco use-related disparities in PR through the implementation of effective tobacco control programs and policies in PR. Metrics to assess success in these areas included the tobacco control strategic plan, the maintenance of the network over time and the passing of smoke-free workplace legislation. Research activities were designed to build infrastructure, collaborations, and capacity for conducting CBPR and to pilot test certain approaches. Metrics used to assess outcomes for research included successful implementation of pilot studies, successful grant applications, and publications. Training, capacity building, and educational activities were designed to increase provider and community-based organization motivation and competence to implement evidence-based tobacco control interventions, like the promotion and referral to the PRQ. Metrics included participation and evaluation of trainings.

\begin{tabular}{|c|c|c|c|c|}
\hline $\begin{array}{l}\text { How did you learn about } \\
\text { the PRQ? }\end{array}$ & $2005, n(\%)$ & $2006, n(\%)$ & $2007, n(\%)$ & $2008, n(\%)$ \\
\hline Physician Referral & $18(2.6)$ & $40(3.6)$ & $103(9.1)$ & $78(7.2)$ \\
\hline Family/Friend & $49(6.1)$ & 185 (16.6) & $153(13.5)$ & $114(10.5)$ \\
\hline Mass Media & $510(72.5)$ & $819(73.7)$ & $717(63.2)$ & $716(65.9)$ \\
\hline Brochure & $10(1.4)$ & $39(3.5)$ & $73(6.4)$ & $50(4.6)$ \\
\hline Other & $116(16.5)$ & $28(2.5)$ & $88(7.8)$ & $128(11.8)$ \\
\hline Total & 703 & 1,111 & 1,134 & 1,086 \\
\hline
\end{tabular}

Note. Referrals are the sum of the physicians' and brochure referrals to the PRQ because these two activities were directly related with the OPP efforts. 


\section{Research Activities}

As noted, most research activities centered on building infrastructure and capacity for research with the PRQ. Quitline data indicated that 4,034 smokers chose to receive the PRQ cessation services between 2005 and 2008 (Table 2). The number of annual smokers receiving cessation services increased from 703 in 2005 to 1,086 in 2008. Although it is impossible to attribute increases in PRQ calls solely to OPP efforts, observational data provide some evidence of OPP impact on PRQ calls. For example, promotional efforts demonstrated the feasibility and effectiveness of using approaches other than mass media advertising to increase calls. In the period from 2005 to 2008, referrals to the PRQ from physicians increased from $2.6 \%$ to $7.2 \%$ and brochure referrals from $1.4 \%$ to $4.6 \%$.

The creation of the infrastructure for evaluating the usage of the PRQ including documentation of referral source of participants set the groundwork for future research projects. For example, during the second and third years of the OPP, the PRQ started collaborating in a clinical trial pilot project, ${ }^{58}$ which evolved into a full-scale research project for tobacco and alcohol use treatment. In 2008, the PR Department of Health Tobacco Control hired an epidemiologist to monitor PRQ use. The PRQ captured data on tobacco use and demographic characteristics. These were periodically compared with data from the Behavior Risk Factor Surveillance Survey and presented at annual tobacco summits. The OPP used this information to target tobacco control activities. Some OPP decisions in response to such data included a revision of the web page, building a Facebook page, and increasing public service announcements aimed at youth.

The OPP has conducted research related to the impact of the smoke-free legislation in collaboration with the Medical Sciences Campus at the University of Puerto Rico, Graduate School of Public Health's researchers and the Puerto Rico Department of Health. ${ }^{50,51}$ These studies showed that the implementation of the smoke-free workplace ban in 2007 resulted in a significant reduction of the exposure to secondhand smoke to casino, pubs, and restaurant workers in PR.

Research activities also resulted in the renewal of the OPP with an expanded scope to include studies related to human papillomavirus vaccine uptake and breast and cervical cancer screening. Another important success was the use of the OPP infrastructure as a venue for the planning and development phases of the PR Cancer Control Plan.

\section{Training and Education}

OPP and the Puerto Rico Department of Health joined efforts in the organization of CT05, which led to subsequent meetings and summits in 2006, 2007, and 2008. Initially, the OPP staff took primary responsibility for organizing the summits, but by 2008 the network partners, in conjunction with the department of health, took full responsibility for planning and implementing these summits. As suggested by the SC, the priority population for the summits was expanded in 2008 to include international expertise and representatives from outside PR (other Latin American countries, Spain, Canada, and the United States). As part of the capacity-building efforts among network members and their collaborators, the OPP developed and delivered four 4-hour workshops for approximately 200 health care professionals each during 2006 and 2007. An initial 4-hour workshop was conducted among health care providers with a focus on how to implement system changes, including using traditional recommendations such as the $5 A$ s (Ask, Advise, Assess, Assist, and Arrange) for helping smokers, but also incorporating strategies for connecting smokers directly to the PRQ. ${ }^{59-73}$ After the initial workshop, additional trainings were conducted reaching approximately 700 health care providers in different geographical areas of PR.

Finally, the OPP conducted three 1-day trainings for PRQ counselors during which 20 counselors were trained. In our efforts to incorporate evidence-based practices for smoking cessation in the regular PRQ services, we sponsored trainings and workshops on motivational interviewing techniques ${ }^{70,71}$ for PRQ counselors. To evaluate these efforts, the PRQ incorporated the use of additional measures to assess factors relevant to the motivational interviewing intervention as well as several measures to assess barriers to cessation for Puerto Rican patients (e.g., stage of change, motivation, alcohol and tobacco use history, abstinence at 3 and 6 months, Interpersonal Support Evaluation List, and Smoking Self-efficacy Scale). These measures were administered at baseline, at several points during treatment, and at follow-up. The PRQ supervisor observed an increase in counseling skills and confidence among PRQ counselors after motivational interviewing training (personal communication). OPP staff 
also provided training and technical support in data collection and management to the PRQ staff. Since OPP started collaborating with the PRQ, their annual reports demonstrated improvements in the quality of data and data management processes, specifically improving their follow-up rates. For example, missing data decreased over time. PRQ records indicated that approximately $60 \%$ of data was complete in 2005 and this increased to $87 \%$ in 2008 .

\section{Community Awareness}

Because there were no promotional materials available to increase awareness of the PRQ, the OPP designed a PRQ logo, which incorporated the PRQ 1-877 number and was approved by the Puerto Rico Department of Health. A variety of materials that included the PRQ logo were developed and distributed (i.e., 5,000 brochures, 5,000 flyers, 300 umbrellas, 300 key chains, 300 executive portfolios, 5,000 business cards, 300 card holders, 500 prescription pads, 5,000 vital signs identification stickers, 300 press kits, 300 posters, and 300 tote bags) during training, educational, and promotional activities. The awareness efforts generated calls to the PRQ and results can be seen in Figure 1. In addition, 15 network organizations included the PRQ promotion information in their organizations' websites, pay checks, and newsletters. Seven network members have also adopted the PRQ as its primary resource for smoking cessation referrals for their clients and employees in their institutions' tobacco cessation programs. From 2005 to 2008 , the OPP distributed four issues of a newsletter by mail to network members and health care providers for a total of a 1,000 newsletters mailed for each issue. Two 30-second public service announcement spots were created for television and three 60 -second spots were developed for radio. The entire budget for this project was $\$ 50,000$ per year for 3 years. The University of Puerto Rico committed an additional $\$ 50,000$ of in-kind resources for salary and materials for the development of this project.

OPP network members and collaborators implemented educational and awareness activities primarily promoting the PRQ and the smoke-free legislation in more than 400 community events and professional presentations reaching diverse audiences, including cancer researchers, physicians, other health care personnel, educators, health communicators, community-based organizations, the media, and the PR community in general. Figure 1 illustrates the network's sustainability efforts after the culmination of the OPP.

Perhaps the most important and sustainable result of the OPP efforts was in the area of public policy. OPP staff and network members participated in public hearings, providing scientific evidence and education to legislators and their staff about the negative health risks and the societal consequences associated with smoking and exposure to secondhand smoke. OPP staff also provided input on the content of the smoke-free workplaces bill that was later enacted into law. ${ }^{74}$ These efforts contributed to establishing a law which banned smoking in

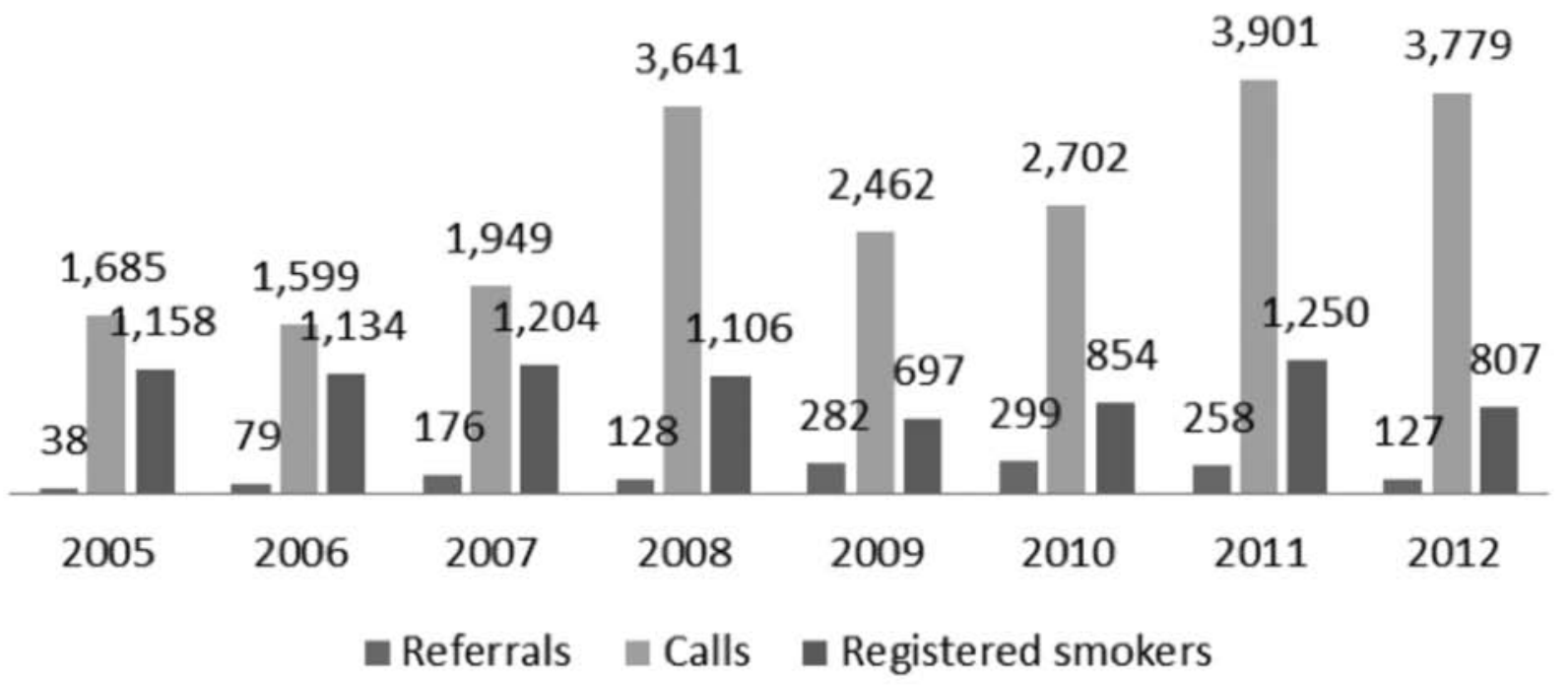

Figure 1. Total Annual Calls, Referrals, and Registered Smokers to the PR Quitline, 2005 Through 2012 
all PR casinos, bars, restaurants, pubs, and in vehicles with any passenger under the age of 13 .

\section{DISCUSSION}

Firmly grounded in principles of CBPR and action, the OPP convened and mobilized a network of academic, community, and health service partners to engage in tobacco control efforts. The core activities of the OPP were designed to increase Network capacity to deliver effective, culturally appropriate, and evidence-based tobacco control interventions and promote the use of the PRQ and the smoke-free legislation. Mobilizing and building capacity in existing organizations increases the potential for sustained community action far beyond the timeframe of any single project. ${ }^{35,41}$ Clear evidence of sustainability is that the ongoing Outreach Network in PR is currently leading and sustaining several of the programs created and implemented during the Outreach Pilot and we continue to advance cancer control research and intervention delivery in PR as a network.

The integration of the network activities within the working plans of the network members' organizations helped to sustain the effort. The continued capacity building of health professionals was also very important in the sustainability of referrals to the PRQ efforts. The policy working group was adopted by the Tobacco Control Office and served to consult on ongoing tobacco control policy evaluation and creation of new policy projects.

Despite political instability and the recent economic crisis, the OPP continued to implement activities in support of program goals. The challenges served as an impetus for careful planning and coordination of tobacco control activities with all network members to optimize limited resources and avoid duplicated efforts. This close collaboration also resulted in a strengthened network.

Community-based outreach programs have tremendous potential for positively influencing tobacco control efforts. Outreach activities can serve as a bridge to bring organizations together under a common goal, and by doing so, can amplify the efforts of each individual organization through greater reach and repetition of critical health messages. Such programs can influence public policy, provide critical training in tobacco control, and increase the utilization of treatment programs. Further, by utilizing a community-based par- ticipatory approach, outreach programs can ensure that they achieve these objectives in a manner that is culturally sensitive and relevant for the local community. The OPP yielded major accomplishments in each of these domains.

Perhaps the two most important successes of the OPP were the creation and maintenance of a network of more than 80 diverse organizations who committed their efforts toward reducing tobacco use, and the shepherding of workplace smoke-free policy in PR. The OPP also succeeded in training more than 700 physicians, dentists, and other health care professionals in implementing system changes for tobacco cessation into clinical practice, and utilizing the PRQ as a primary resource for cessation. Research activities conducted in collaboration with the PRQ revealed a shift in the source of PRQ callers away from costly mass media promotion, toward a greater proportion of callers referred through their health care providers and via low-cost print materials.

Finally, the prevalence of smoking among adults in PR declined from $14 \%$ in 2005 to $11.6 \%$ in 2008 . These changes cannot be attributed totally to the OPP efforts, but can be attributed to the sum of all tobacco control efforts in PR. Our tobacco control effort in PR stands in stark contrast with the United States, where smoking prevalence rates have stagnated over the last decade at a rate of approximately $20 \%$. The experience and evidence from the OPP indicate that a communitybased outreach program can result in meaningful, real-world change in tobacco use, the leading preventable cause of death and disability in the United States.

\section{LESSONS LEARNED}

Lessons learned during the OPP included the realization that the inclusion of additional partners (health care providers were highlighted as a key group to incorporate into the network) into the OPP would broaden the initiatives beyond the promotion of the PRQ and support and promote the smoke-free ban. The OPP use CBPR principles to align their objectives and aims with the interests of the network and collaborators, and also help in the dissemination of results to fulfill the need to expand activities to multiple geographical locations (i.e., beyond the major population center of San Juan). Network members also identified several challenges: time constraints, limited funding to implement outreach activities, tobacco control was not always perceived as a prior- 
ity by managers and perceived lack of professional competence in tobacco-related topics. Additionally, network participants recommended continuing providing information regarding tobacco-related research and other accomplishments by collaborators, integrating tobacco awareness within other chronic diseases campaigns throughout the year, and continuing trainings on evidence-based practices for tobacco control.

There is powerful evidence that comprehensive tobacco control programs effectively reduce tobacco use, but such progress can be halted or even reversed when programs are reduced or discontinued. The description of the development and implementation of the OPP provides an example of how community networking is feasible, sustainable, and can contribute to tobacco control. Empowering community organiza- tions to take action via networking, education, research, and the provision of tangible solutions for service provision not only increase awareness of such services, but may also facilitate larger changes in tobacco control efforts throughout society. By working with existing organizations using a communitybased participatory approach and by modifying program goals based on community input, OPP helped ensure that the tobacco-control activities carried out in PR were relevant and appropriate to community needs and capacity, as well as sustainable. Importantly, network members also reiterated that an outreach program's sustainability relies on building the capacity of its members. Community networks such as the OPP should continue to be analyzed in terms of their governance, accountability, operations, risks, and benefits.

\section{REFERENCES}

1. U.S. Centers for Disease Control and Prevention (CDC). Current cigarette smoking among adults-United States, 2011. MMWR Morb Mortal Wkly Rep. 2012;61(44):889-94.

2. Puerto Rico Department of Health. Estadísticas Vitales del Departamento de Salud de Puerto Rico. San Juan, PR: Author; 2010.

3. U.S. Centers for Disease Control and Prevention (CDC). State-specific prevalence and trends in adult cigarette smoking-United States, 1998-2007. MMWR Morb Mortal Wkly Rep. 2009;58(9):221-226.

4. Suarez E, Calo WA, Hernandez EY, Diaz EC, Figueroa NR, Ortiz AP. Age-standardized incidence and mortality rates of oral and pharyngeal cancer in Puerto Rico and among NonHispanics Whites, Non-Hispanic Blacks, and Hispanics in the USA. BMC Cancer. 2009;9:129.

5. International Agency for Cancer Research. GLOBOCAN database: Summary table by cancer. Lyon, France: Author; 2002.

6. Mental Health and Anti Addiction Services Administration. Puerto Rico substance abuse treatment needs assessment study. Bayamon, PR: Author; 1991.

7. U.S. Centers for Disease Control and Prevention (CDC). A practical guide to working with health-care systems on tobaccouse treatment, and the treating tobacco use and dependence clinical practice guideline. Atlanta, GA: Author; 2000.

8. U.S. Centers for Disease Control and Prevention (CDC). Statespecific prevalence of cigarette smoking and quitting among adults-United States, 2004. MMWR Morb Mortal Wkly Rep. 2005;54(44):1124-7.

9. U.S. Centers for Disease Control and Prevention (CDC). State Medicaid coverage for tobacco-dependence treatmentsUnited States, 2007. MMWR Morb Mortal Wkly Rep. 2009; 58(43):1199-204.
10. An LC, Zhu SH, Nelson DB, Arikian NJ, Nugent S, Partin $\mathrm{MR}$, et al. Benefits of telephone care over primary care for smoking cessation: a randomized trial. Arch Intern Med. 2006;166(5):536-42.

11. Fiore MC, Jaen CR. A clinical blueprint to accelerate the elimination of tobacco use. JAMA. 2008;299(17):2083-5.

12. Woods SS, Haskins AE. Increasing reach of quitline services in a US state with comprehensive tobacco treatment. Tob Control. 2007;16 Suppl 1:i33-6.

13. Keller PA, Feltracco A, Bailey LA, Li Z, Niederdeppe J, Baker $\mathrm{TB}$, et al. Changes in tobacco quitlines in the United States, 2005-2006. Prev Chronic Dis. 2010;7(2):A36.

14. Stead LF, Perera R, Lancaster T. A systematic review of interventions for smokers who contact quitlines. Tob Control. 2007;16 Suppl 1:i3-i8.

15. Zhu SH, Tedeschi GJ, Anderson CM, Pierce JP: Telephone counseling for smoking cessation: what's in a call? J Couns Dev. 1996;75:93-102.

16. Zhu SH, Pierce JP. A new scheduling method for time-limited counseling. Prof Psychol Res Pr. 1995;26:624-5.

17. Ortiz AP, Diaz-Toro EC, Calo WA, Correa-Fernandez V, Cases A, Santos-Ortiz MC, et al. Characteristics of smokers accessing the Puerto Rico Quitline. P R Health Sci J. 2008;27(3):213-219.

18. Stead LF, Lancaster T. Telephone counseling for smoking cessation. Cochrane Database Syst Rev. 2001;(2):CD002850.

19. Lando HA, Rolnick S, Klevan D, Roski J, Cherney L, Lauger G. Telephone support as an adjunct to transdermal nicotine in smoking cessation. Am J Public Health. 1997;87(10):1670-4. 
20. Lichtenstein E, Glasgow RE, Lando HA, Ossip-Klein DJ, Boles SM. Telephone counseling for smoking cessation: rationales and meta-analytic review of evidence. Health Educ Res. 1996;11(2):243-57.

21. Glasgow RE, Lando H, Hollis J, McRae SG, La Chance PA. A stop-smoking telephone help line that nobody called. Am J Public Health. 1993;83(2):252-253.

22. Sheffer CE, Brackman SL, Cottoms N, Olsen M. Understanding the barriers to use of free, proactive telephone counseling for tobacco dependence. Qual Health Res. 2011;21(8):1075-85.

23. Cotter T, Perez DA, Dessaix AL, Bishop JF. Smokers respond to anti-tobacco mass media campaigns in NSW by calling the Quitline. N S W Public Health Bull. 2008;19(3-4):68-71.

24. Donovan RJ, Boulter J, Borland R, Jalleh G, Carter O. Continuous tracking of the Australian National Tobacco Campaign: Advertising effects on recall, recognition, cognitions, and behavior. Tob Control. 2003;12 Suppl 2:ii30-9.

25. Niederdeppe J, Fiore MC, Baker TB, Smith SS. Smokingcessation media campaigns and their effectiveness among socioeconomically advantaged and disadvantaged populations. Am J Public Health. 2008;98(5):916-924.

26. Carroll T, Rock B. Generating Quitline calls during Australia's National Tobacco Campaign: Effects of television advertisement execution and programme placement. Tob Control. 2003;12 Suppl 2:ii40-4.

27. Miller CL, Wakefield M, Roberts L. Uptake and effectiveness of the Australian telephone Quitline service in the context of a mass media campaign. Tob Control. 2003;12 Suppl 2:ii53-8.

28. Miller CL, Hill DJ, Quester PG, Hiller JE. Impact on the Australian Quitline of new graphic cigarette pack warnings including the Quitline number. Tob Control. 2009;18(3):235-7.

29. Fichtenberg CM, Glantz SA. Effect of smoke-free workplaces on smoking behavior: systematic review. BMJ. 2002; 325(7357):188.

30. Dobson R. Italy's smoking ban has led to an $8 \%$ drop in tobacco consumption. Br Med J. 2005;331(7526):1159.

31. Chan SS, Wong DC, Fong DY, Leung AY, Mak YW, Lam DO, et al. Short-term impact of new smoke free legislation on the utilization of a quitline in Hong Kong. Nicotine Tob Res. 2009;11(4):356-61.

32. Hackshaw L, McEwen A, West R, Bauld L. Quit attempts in response to smoke-free legislation in England. Tob Control. 2010;19(2):160-4.

33. Hopkins DP, Razi S, Leeks KD, Priya Kalra G, Chattopadhyay SK, Soler RE, et al. Smokefree policies to reduce tobacco use. A systematic review. Am J Prev Med. 2010;38(2 Suppl):S275-89.

34. U.S. Centers for Disease Control and Prevention (CDC). State preemption of local smoke-free laws in government work sites, private work sites, and restaurants-United States, 2005-2009. MMWR Morb Mortal Wkly Rep. 2010;59(4):105-8.

35. Israel BA, Schulz AJ, Parker EA, Becker AB. Review of community-based research: assessing partnership approaches to improve public health. Annu Rev Public Health. 1998;19:173-202.
36. Israel BA, Schulz AJ, Parker EA, Becker AB, CommunityCampus Partnerships for Health. Community based participatory research: Policy recommendations for promoting a partnership approach in health research. Educ Health. 2001;14(2):182-97.

37. Leung MW, Yen IH, Minkler M. Community based participatory research: A promising approach for increasing epidemiology's relevance in the 21st century. Int J Epidemiol. 2004;33(3):499-506.

38. Smith SS, Beckley T, Fiore MC. Health care provider use of guideline-based smoking cessation interventions: results from the 2003 Wisconsin Tobacco Survey. WMJ. 2005;104(4):28-31.

39. Reiner M, Petereit DG. Community-based participatory research: providers, patient, and community in partnership to improve health disparities. J Am Board Fam Med. 2008;21(1):78-9.

40. Israel BA, Coombe CM, Cheezum RR, Schulz AJ, McGranaghan RJ, Lichtenstein R, et al. Community based participatory research: a capacity-building approach for policy advocacy aimed at eliminating health disparities. Am J Public Health. 2010;100(11):2094-102.

41. Minkler M. Community-based research partnerships: challenges and opportunities. J Urban Health. 2005;82 Suppl 2:ii3-12.

42. Woods SS, Jensen LB, Schulz P, Barnason S, Graham J, Rasmussen D, et al. Collaborative research: A community approach. Clin Nurse Spec. 2000;14(1):13-16.

43. Samuels B, Glantz SA. The politics of local tobacco control. JAMA. 1991;266(15):2110-7.

44. Hahn EJ. Smokefree legislation: a review of health and economic outcomes research. Am J Prev Med. 2010;39 Suppl 1:S66-76.

45. Shipan CR, Volden C. Bottom-up federalism: the diffusion of anti-smoking policies from US cities to states. Am J Poli Sci. 2006;50(4):825-43.

46. Wetter DW, Mazas C, Daza P, Nguyen L, Fouladi RT, Li Y, et al. Reaching and treating Spanish speaking smokers through the National Cancer Institute's Cancer Information Service. A randomized controlled trial. Cancer. 2007;109(2 Suppl):406-13.

47. Borland R, Balmford J, Bishop N, Segan C, Piterman L, McKayBrown $\mathrm{L}$, et al. In-practice management versus quitline referral for enhancing smoking cessation in general practice: A cluster randomized trial. Fam Pract. 2008;25(5):382-9.

48. Burns EK, Levinson AH. Reaching Spanish-speaking smokers: State-level evidence of untapped potential for QuitLine utilization. Am J Public Health. 2010;100 Suppl 1:S165-170.

49. Correa-Fernández V, Calo WA, Diaz-Toro EC, Mazas C, Reitzel L, Mejia L, Cases A, et al. Simultaneous treatment of tobacco dependence and at-risk drinking among Puerto Ricans. Poster presentation at CRCHD Cancer Health Disparities Program Meetings 2011; July 12-15, 2011; Bethesda, Washington, DC.

50. Marin HA, Diaz-Toro E. The effect of the smoke-free workplace policy in the exposure to secondhand smoke in restaurants, pubs, and discos in san Juan, Puerto Rico. P R Health Sci J. 2010;29(3):279-85. 
51. Marin, HA, Díaz-Toro, EC. Reduced exposure to environmental tobacco smoke at casinos in Puerto Rico after the implementation of a workplace smoking ban in 2007: A pre-post design. PR Health Sci J. 2011;30(4):182-7

52. U.S. Centers for Disease Control and Prevention (CDC). Comprehensive smoke-free laws-50 largest U.S. cities, 2000 and 2012. MMWR Morb Mortal Wkly Rep. 2012;61(45):914-7.

53. Bartosch WJ, Pope GC. The economic effect of smoke-free restaurant policies on restaurant businesses in Massachusetts. J Public Health Manag Pract. 1999;5(1):53-62.

54. Mintrom M. Policy entrepreneurs and the diffusion of innovation. Am J Pol Sci. 1997;41(3):738-770.

55. Satterlund TD, Cassady D, Treiber J, Lemp C. Barriers to adopting and implementing local-level tobacco control policies. J Community Health. 2011;36(4):616-23.

56. Satterlund TD, Cassady D, Treiber J, Lemp C. Strategies implemented by 20 local tobacco control agencies to promote smoke-free recreation areas, California, 2004-2007. Prev Chronic Dis. 201;8(5):A111.

57. Calo WA, Fernández ME, Rivera M, Díaz EC, CorreaFernández V, Pattatucci A, et al. Assessing awareness and use of evidence-based programs for cancer control in Puerto Rico. J Cancer Educ. 2012;27(3):486-93.

58. Figueroa PY, Flores A, Reitzel LR, Costello T, Mazas CA, Mejia $\mathrm{L}$, et al. Motivation and Problem Solving (MAPS) Treatment for smoking cessation and alcohol risk reduction among SpanishSpeaking Puerto-Ricans: A pilot study. Albuquerque, NM: Motivational Interviewing Network of Trainers Forum; 2008.

59. Borland R, Segan CJ, Livingston PM, Owen N. The effectiveness of callback counseling for smoking cessation: a randomized trial. Addiction. 2001;96:881-9.

60. Zhu SH, Anderson CM, Tedeschi GJ, Rosbrook B, Johnson CE, Byrd M, et al. Evidence of real-world effectiveness of a telephone quitline for smokers. N Engl J Med. 2002;347(14):1087-93.

61. Macleod ZR, Charles MA, Arnaldi VC, Adams IM. Telephone counseling as an adjunct to nicotine patches in smoking cessation: a randomized controlled trial. Med J Aust. 2003;79:349-52.

62. Helgason AR, Tomson T, Lund KE, Galanti R, Ahnve S, Gilljam $\mathrm{H}$. Factors related to abstinence in a telephone helpline for smoking cessation. Eur J Public Health. 2004;14:306-10.
63. Taylor CB, Curry SJ. Implementation of evidence-based tobacco use cessation guidelines in managed care organizations. Ann Behav Med. 2004;27(1):13-21.

64. Revell CC, Schroeder SA. Simplicity matters: using systemlevel changes to encourage clinician intervention in helping tobacco users quit. Nicotine Tob Res. 2005;7 Suppl 1:S67-9.

65. Gordon JS, Andrews JA, Crews KM, Payne TJ, Severson HH. The 5A's vs 3A's plus proactive quitline referral in private practice dental offices: Preliminary results. Tob Control. 2007;16(4):285-8.

66. Bentz CJ, Bayley KB, Bonin KE, Fleming L, Hollis JF, Hunt JS, et al. Provider feedback to improve 5A's tobacco cessation in primary care: a cluster randomized clinical trial. Nicotine Tob Res. 2007;9(3):341-9.

67. Woods SS, Haskins AE. Increasing reach of quitline services in a US state with comprehensive tobacco treatment. Tob Control. 2007;16 Suppl 1:i33-6.

68. Borland R, Balmford J, Segan C, Livingston P, Owen N. The effectiveness of personalized smoking cessation strategies for callers to a Quitline service. Addiction. 2003;98(6):837-46.

69. Gollust SE, Schroeder SA, Warner KE. Helping smokers quit: understanding the barriers to utilization of smoking cessation services. Milbank Q .2008;86(4):601-27.

70. Miller WR, Rose GS. Toward a theory of motivational interviewing. Am Psychol. 2009;64(6):527-37.

71. Hettema J, Steele J, Miller WR. Motivational interviewing. Annu Rev Clin Psychol. 2005;1:91-111.

72. Stead LF, Lancaster T, Perera R. Telephone counseling for smoking cessation. Cochrane DB Syst Rev. 2004;4.

73. Stead LF, Perera R, Lancaster T. A systematic review of interventions for smokers who contact quitlines. Tob Control. 2007;16:i3-i8.

74. Puerto Rico's Law No. 40 of 1993 as amended by Law No. 66 of 2006 . 